\title{
Psychological Predictors of Weight Loss Success Following Roux-en-Y Gastric Bypass
}

\author{
${ }^{1}$ Surgery, Private Practice, USA \\ ${ }^{2}$ Kaiser Permanente, Richmond, $C A$ \\ ${ }^{3}$ Department of Surgery, University of California, CA \\ ${ }^{4}$ Psychology, Private Practice, $C A$ \\ ${ }^{5}$ Department of Surgery, Scripps Green Hospital, CA
}

Hazem N Shamseddeen ${ }^{1 *}$, Rouzbeh Mostaedi², Jawad Ali ${ }^{3}$, Stancil JL Hutchinson ${ }^{4}$, William D Fuller ${ }^{5}$, Grant L Hutchinson $^{4}$, Karen A Hutchinson ${ }^{4}$ and Mohamed R Ali ${ }^{2}$

Submission: July 7, 2017; Published: August 04, 2017

*Corresponding author: Mohamed R Ali, Professor of Surgery, Department of Surgery, University of California, USA, Tel: 916 734-4596;

Fax: 916 734-3951; Email: mrali@ucdavis.edu

\begin{abstract}
Background: Weight loss is a primary outcome measure for the success of Roux-En-Y gastric bypass (RYGB). Much attention has been paid to the negative effects of psychology on postoperative weight loss. We sought to identify personality traits and eating habits that predict weight loss success following RYGB.

Methods: A single psychologist prospectively evaluated 346 patients, who subsequently underwent laparoscopic RYGB. Psychological evaluation included Minnesota Multiphasic Personality Inventory Short Form (MMPI-2 SF) and long form subscales (MMPI-2 RC) as well as Overeating Questionnaire (OQ). Demographic, anthropomorphic, and clinical data were collected before and after surgery.

Results: The overall mean percent excess weight loss (\%EWL) was 71.34+/-24.35\%. Of the ten MMPI-2 SF scales, Masculine-Feminine (MF), Hypochondriasis (HS), Schizophrenia (SZ), and Mania (MA) correlated to \%EWL, but only MA reached statistical significance ( $r=-0.24$, $p<0.005)$. Of the nine MMPI-2 RC scales, Somatic Complaints (SC), Cynicism (CY), Aberrant Experiences (AE), and Hypomanic Activation (HA) correlated to \%EWL, with AE $(r=-0.17, \mathrm{p}<0.05)$ and $\mathrm{HA}(\mathrm{r}=-0.15, \mathrm{p}<0.005)$ reaching statistical significance. Of the ten OQ scales, Health Habits $(\mathrm{HH})$, Rationalizations (RA), and Motivation to Lose Weight (MLW) correlated to EWL, with MLW reaching statistical significance ( $r=-0.59, \mathrm{p}<0.005)$.

Conclusion: This study corroborates the effectiveness of RYGB in achieving weight loss and shows that psychological factors can impact weight loss success. While several personality traits and eating habits correlate with improved weight loss, MA, AE, HA, and MLW seemed to have particularly strong correlations with weight loss success.
\end{abstract}

Keywords: Morbid obesity; Roux-en-Y gastric bypass; Psychological evaluation; MMPI-2; Overeating questionnaire; Weight loss; Bariatric surgery

\section{Introduction}

Obesity has been increasing globally over the last three decades, and its national and global burden has been projected to grow in the future $[1,2]$. Bariatric surgery is an effective tool for the management of morbid obesity, and several studies have reported decreased mortality and morbidity after bariatric surgery compared to conventional therapy $[3,4]$. Preoperative psychological screening of bariatric patients is performed at many centers specializing in weight loss surgery, following the consensus statement on bariatric surgery from the National Institutes of Health $[5,6]$. This statement, however, did not specify the nature of the evaluation, characterize how to utilize the information to determine surgical candidacy, or identify the role such data may play in the postoperative management of patients.

The determinants of obesity are complex and might involve several environmental and psychosocial factors that interact together. Several studies have correlated the psychosocial factors related to obesity and eating habits with surgical outcomes specific to weight loss and weight loss maintenance [7-13]. Other studies focused on the relationships between behavioral traits and postoperative patient compliance and weight regain $[14,15]$. 


\section{Current Research in Diabetes \& Obesity Journal}

Preoperative psychological screening is a prominent component of our bariatric surgery program. This screening focuses on identifying psychiatric disorders, characterizing personality traits, and assessing attitudes toward eating. We sought to determine the effects of personality traits and eating habits on weight loss after Roux-en-Y gastric bypass (RYGB).

\section{Materials and Methods}

Over five years, a single psychologist prospectively evaluated 605 patients in preparation for bariatric surgery at our institution. Comorbidity and anthropomorphic data were also collected prospectively for clinical purposes. Patient records were then reviewed under approval from the Institutional Review Board for the purposes of this study. The single inclusion criterion for this study was completion of a minimum of 10 months of postoperative follow-up.

Psychological evaluation primarily included Minnesota Multiphasic Personality Inventory (MMPI-2) and the Overeating Questionnaire (OQ). Initially, we relied on the long form (MMPI2), which consists of 567 questions, and evaluated patients based on the MMPI-2 Restructured Clinical (RC) scales. Over the study period, the algorithm for psychological testing evolved with experience. The MMPI-2 Short Form (MMPI-2 SF) (which consists of the first 370 questions on the MMPI-2) was substituted for MMPI-2 RC to minimize the discomfort expressed by morbidly obese patients during the long period of testing. Additionally, the $\mathrm{OQ}$ was not yet available at the beginning of the study period. Once available, we chose to include this questionnaire in an attempt to more fully evaluate bariatric surgery candidates. Thus, the study population contains patients who completed the MMPI2 SF only (Group 1, $\mathrm{n}=114$ ), the entire MMPI-2 only (Group 2, $\mathrm{n}=44$ ) or the OQ only (Group 3, n=23). The majority of patients completed the entire MMPI-2 and the OQ (Group 4, n=165). Thus, 209 patients completed the entire MMPI-2. Since the MMPI-2 SF simply consists of the first 370 questions of the MMPI-2, MMPI2 SF subscales were available for these 209 patients in addition to the 114 patients who completed MMPI-2 SF only, for a total of 323 patients. OQ data were available for the 23 patients who only completed this form and the 165 patients who completed OQ in addition to MMPI-2. Ultimately, MMPI-2 RC data were available for 209 patients, MMPI-2 SF data were available for 323 patients, and OQ data were available for 188 patients.

Weight loss data were collected during clinical encounters with the bariatric surgery program preoperatively and at each postoperative appointment. All patients in this study underwent laparoscopic Roux-en-Y gastric bypass (LRYGB). No other primary bariatric procedures were performed at our program during the study period. All data are presented as mean+/standard deviation. Data were analyzed using ANOVA for multiple comparisons of means of continuous variables and Fisher's exact test for comparisons of discrete variables. Pearson and Spearman coefficients were calculated to examine correlations between questionnaire variables and postoperative excess weight loss. Statistical significance was set at alpha $=0.05$ for all analyses.

\section{Results}

Over a five-year period, 605 candidates for bariatric surgery underwent pre-surgical psychological testing by a single psychologist. At the time of data analysis, 346 patients had undergone RYGB and achieved postoperative follow-up between 10 to 24 months. The remaining patients had not undergone surgery $(n=114)$ or had not reached the minimum follow-up of 10 months $(n=145)$. Of the patients who had not reached 10 months of follow-up, 57 patients did not return to clinic and, thus, werelost to follow-up. The study population consisted of 346 patients with a mean age of $43.5+/-9.4$ years (Table 1 ). The patients were primarily females (85.6\%). Mean preoperative weight was $125.9+/-21.2 \mathrm{~kg}$, and mean preoperative excess weight was $56.3+18.2 \mathrm{~kg}$. On average, patients were able to achieve $71.3+/-24.4 \%$ excess weight loss. Preoperative psychological evaluation was accomplished via MMPI-2 SF ( $n=323)$, MMPI-2 RC $(\mathrm{n}=209)$, and OQ $(\mathrm{n}=188)$, with 165 patients completing all three instruments. There were no significant differences in demographic data among the patient groups (1-4 as described in methods section) in terms of age, gender proportions, preoperative excess weight, or postoperative excess weight loss.

Table 1: Demographic data.

\begin{tabular}{|c|c|}
\hline $\mathbf{N}$ & $\mathbf{3 4 6}$ \\
\hline Age (years) & $43.5+/-9.4$ \\
\hline \% Female & 85.6 \\
\hline Preop Weight $(\mathrm{kg})$ & $125.9+/-21.2$ \\
\hline Preop Excess Weight $(\mathrm{kg})$ & $56.3+/-18.2$ \\
\hline \% Excess Weight Loss & $71.3+/-24.4$ \\
\hline
\end{tabular}

Correlation analyses between MMPI-2 SF, MMPI-2 RC, and $\mathrm{OQ}$ subscales and the percentage of excess weight loss (\%EWL) following RYGB are summarized in Table 2. Only four of the ten subscales of the MMPI-2 SF correlated with greater postoperative \%EWL. The masculine-feminine $(r=-0.10, p=0.07)$ and schizophrenia ( $\mathrm{r}=-0.10, \mathrm{p}=0.07)$ subscales showed a correlation with \%EWL but did not reach statistical significance. Hypochondriasis ( $\mathrm{r}=-0.12, \mathrm{p}=0.03)$ and mania ( $\mathrm{r}=-0.25$, $\mathrm{p}<0.0001$ ), on the other hand, significantly correlated with greater \%EWL following LRYGB. The remaining subscales (depression, hysteria, psychopathic deviation, paranoia, psychasthenia, and social introversion) did not correlate with \%EWL. Similarly, four of the nine MMPI-2 RC subscales exhibited a correlation with $\%$ EWL. Somatic complaints $(\mathrm{r}=-0.13, \mathrm{p}=0.06)$ and cynicism $(\mathrm{r}=-$ $0.12, \mathrm{p}=0.08$ ) demonstrated correlations with \%EWL that were not significant. Statistically significant correlations with \%EWL were identified for hypomanic activation $(\mathrm{r}=-0.16, \mathrm{p}=0.02)$ and aberrant experiences $(r=-0.21, p=0.002)$. The remaining subscales (demoralization, low positive emotions, antisocial behavior, ideas of persecution, and dysfunctional negative emotions) did 


\section{Current Research in Diabetes \& Obesity Journal}

not correlate with \%EWL. As for $\mathrm{OQ}$, the rationalizations ( $\mathrm{r}=-$ $0.12, \mathrm{p}=1.0)$ and health habits $(\mathrm{r}=-0.14, \mathrm{p}=0.06)$ exhibited nonsignificant correlations. The motivation to lose weight subscale, however, correlated strongly with \%EWL, as evidenced by $\mathrm{r}=-$ 0.59 . This correlation was statistically significant $(p<0.0001)$.
The remaining $\mathrm{OQ}$ subscales (overeating, undereating, craving, expectations about eating, body image, social isolation, and affective disturbance) did not demonstrate a relationship with $\%$ EWL

Table 2: Correlation analyses between psychological testing elements and postoperative weight loss.

\begin{tabular}{|c|c|c|c|c|c|c|c|c|}
\hline \multicolumn{3}{|c|}{ MMPI-2 SF ${ }^{1}(n=323)$} & \multicolumn{3}{|c|}{ MMPI-2 RC $(n=209)$} & \multicolumn{3}{|c|}{ Overeating Questionnaire $(n=188)$} \\
\hline Variable & Corr & $\mathbf{p}$ & Variable & Corr & $\mathbf{p}$ & Variable & Corr & p \\
\hline Hypochondriasis & + & 0.033 & Demoralization & - & NS & Overeating & - & NS \\
\hline Depression & - & NS & $\begin{array}{c}\text { Somatic } \\
\text { complaints }\end{array}$ & + & NS & Under eating & - & NS \\
\hline Hysteria & - & NS & $\begin{array}{l}\text { Low positive } \\
\text { emotions }\end{array}$ & - & NS & Craving & - & NS \\
\hline $\begin{array}{c}\text { Psychopathic } \\
\text { deviation }\end{array}$ & - & NS & Cynicism & + & NS & $\begin{array}{l}\text { Expectations } \\
\text { about eating }\end{array}$ & - & NS \\
\hline $\begin{array}{l}\text { Masculine- } \\
\text { feminine }\end{array}$ & + & NS & $\begin{array}{l}\text { Antisocial } \\
\text { behavior }\end{array}$ & - & NS & Rationalizations & + & NS \\
\hline Paranoia & - & NS & $\begin{array}{l}\text { Ideas of } \\
\text { persecution }\end{array}$ & - & NS & $\begin{array}{l}\text { Motivation to } \\
\text { lose weight }\end{array}$ & + & 0.003 \\
\hline Psychasthenia & - & NS & $\begin{array}{l}\text { Dysfunctional } \\
\text { negative } \\
\text { emotions }\end{array}$ & - & NS & Health habits & + & NS \\
\hline Schizophrenia & + & NS & $\begin{array}{c}\text { Aberrant } \\
\text { experiences }\end{array}$ & + & 0.026 & Body image & - & NS \\
\hline Mania & + & 0.002 & $\begin{array}{l}\text { Hypomanic } \\
\text { activation }\end{array}$ & + & 0.002 & Social isolation & - & NS \\
\hline Social introversion & - & NS & & & & $\begin{array}{c}\text { Affective } \\
\text { disturbance }\end{array}$ & - & NS \\
\hline
\end{tabular}

\section{Discussion}

Morbid obesity is a multifactorial disease which has been growing at an alarming rate [16]. The current epidemic nature of morbid obesity has motivated a great deal of research aimed at elucidating its causes. It has become clear that the predisposition to obesity begins with genetic tendencies [17]. The resulting metabolic dysregulation disrupts energy homeostasis and leads to the accumulation of adipose tissue [18]. The adipose tissue, in turn, perpetuates the metabolic abnormalities through significant endocrine activity which affects many organ systems $[19,20]$.

Yet, there are documented psychosocial and environmental facets to this disease [21]. It is unclear whether this is simply the result of individual and societal behaviors or the result of interaction of the brain within the disordered metabolic milieu. Regardless of the cause, the impact of behavior and personality on the development of obesity are undeniable. Psychological screening is considered an important component of comprehensive care of the bariatric surgery patient $[5,6]$. While several studies have discussed the psychological profiles of bariatric surgery patients, there is little consensus as to the elements that should be considered when evaluating patients [22,23]. While no current instrument can reliably predict patient weight loss outcomes, there is evidence that eating behaviors and personality traits can be useful in assessing bariatric surgery candidates [22,24].
The MMPI-2 questionnaire is widely-used to evaluate psychosomatic conditions and to identify personality traits $[25,26]$. This instrument is valid for assessing obese patients [27]. Some investigations have demonstrated that obese patients have an increased prevalence of psychopathology on MMPI-2 [27], while other work did not find a correlation between psychopathology level and obesity [28]. The $O Q$ is an 80-item instrument that measures attitudes toward obesity and eating. The OQ provides scores in ten areas. Six areas reflect general health habits and assess psychosocial functioning. The other four areas target psychosocial issues that coexist with obesity. The $\mathrm{OQ}$ is reputed to assist in planing effective weight loss efforts for patients. In our study, personality characteristics and attitudes toward eating correlated with \%EWL at 12 to 24 months following LRYGB. Between the RC subscales and the SF subscales, eight elements of MMPI-2 correlated with better \%EWL, as indicated by $r<-0.1$, with four of these elements (hypochondriasis, mania, aberrant experiences, and hypomanic activation) reaching statistical significance (Table 2). Three subscales of the OQ correlated with improved \%EWL, but only one (motivation to lose weight) was statistically significant (Table 2).

Other investigators have used MMPI-2 to evaluate patients in preparation for RYGB $[13,29]$. One such study identified that some scales were associated with better weight loss outcomes 


\section{Current Research in Diabetes \& Obesity Journal}

at six months post surgery [13]. Furthermore, some scales were associated with weight loss at various postoperative intervals, such that the investigators suggested a potential role for timedependent postoperative patient management strategies [13]. Another study identified an "emotionally disturbed" patient group, based on the MMPI-2, and found that these patients were less compliant and had decreased weight loss [29].

In terms of evaluating attitudes toward eating, Powers et al studied eating pathology in bariatric surgery patients preoperatively and found no relationship between presurgical eating pathology and weight loss [30]. Yet, in a review of the literature, Niego et al found that patients with preoperative binge eating behavior were more likely to continue the eating pathology following surgery and achieve less weight loss [31] These assertions are supported by Kalarchian et al, who found that the recurrence of binge eating after surgery was associated with weight regain [9]. Finally, it has been reported that risk for weight regain following bariatric surgery can be predicted during preoperative screening, as primarily indicated by increased food urges, decrease well-being, and concerns over addictive behaviors [14].

Our study differs from a large portion of the available literature in that we focused on identifying predictors of weight loss success rather than weight loss failure. We were able to identify correlations between improved weight loss and certain psychological traits and eating habits. In our practice, we plan to combine our findings with the available literature to preoperatively identify traits that may motivate a patient to succeed as well as those that may predispose to failure. The ultimate goal is to address the predictors of failure while promoting the predictors of success in an attempt to maximize the benefits of bariatric surgery to the patient. Psychological screening will continue to be part of preoperative screening for bariatric surgery in many programs. We were able to identify personality and eating-associated traits that correlated to weight loss success followingLRYGB. Further investigation is warranted in this field to more fully understand how to support patients along the weight loss journey and maximize postoperative weight loss and weight loss maintenance.

\section{References}

1. Kelly T, Yang W, Chen CS, Reynolds K, He J (2008) Global burden of obesity in 2005 and projections to 2030. Int J Obes (Lond) 32(9): 1431-1437.

2. Wang Y, Beydoun MA, Liang L, Caballero B, Kumanyika SK (2008) Will all Americans become overweight or obese? estimating the progression and cost of the US obesity epidemic. Obesity (Silver Spring) 16(10): $2323-2330$

3. Adams TD, Gress RE, Smith SC, Halverson RC, Simper SC, et al. (2007) Long-term mortality after gastric bypass surgery. N Engl J Med 357(8): 753-761.

4. Sjostrom L, Narbro K, Sjostrom CD, Karason K, Larsson B, et al. (2007) Effects of bariatric surgery on mortality in Swedish obese subjects. N Engl J Med 357(8): 741-752.
5. Bauchowitz AU, Gonder Frederick LA, Olbrisch ME, Azarbad L, Ryee MY, et al. (2005) Psychosocial evaluation of bariatric surgery candidates: a survey of present practices. Psychosom Med 67(5): 825-832.

6. NIH conference (1991) Gastrointestinal surgery for severe obesity. Consensus Development Conference Panel. Ann Intern Med 115(2): 956-961.

7. de Zwaan M, Mitchell JE, Howell LM, Monson N, Swan Kremeier L, et al. (2003) Characteristics of morbidly obese patients before gastric bypass surgery. Compr Psychiatry 44: 428-434.

8. Fabricatore AN, Crerand CE, Wadden TA, Sarwer DB, Krasucki JL (2006) How do mental health professionals evaluate candidates for bariatric surgery? Survey results. Obes Surg 16(5): 567-573.

9. Kalarchian MA, Marcus MD, Wilson GT, Labouvie EW, Brolin RE (2002) Binge eating among gastric bypass patients at long-term follow-up. Obes Surg 12(2): 270-275.

10. Fischer S, Chen E, Katterman S, Roerhig M, Bochierri-Ricciardi L, et al. (2007) Emotional eating in a morbidly obese bariatric surgery-seeking population. Obes Surg 17(6): 778-784.

11. Sarwer DB, Wadden TA, Fabricatore AN (2005) Psychosocial and behavioral aspects of bariatric surgery. Obes Res 13(4): 639-648.

12. Thonney B, Pataky Z, Badel S, Bobbioni Harsch E, Golay A (2010) The relationship between weight loss and psychosocial functioning among bariatric surgery patients. Am J Surg 199(2): 183-188.

13. Belanger SB, Wechsler FS, Nademin ME, Virden TB (2010) Predicting outcome of gastric bypass surgery utilizing personality scale elevations, psychosocial factors, and diagnostic group membership. Obes Surg 20(10): 1361-1371.

14. Odom J, Zalesin KC, Washington TL, Miller WW, Hakmeh B, et al. (2010) Behavioral predictors of weight regain after bariatric surgery. Obes Surg 20(3): 349-356.

15. Boeka AG, Prentice Dunn S, Lokken KL (2010) Psychosocial predictors of intentions to comply with bariatric surgery guidelines. Psychol Health Med 15(2): 188-197.

16. Weinsier RL, Hunter GR, Heini AF, Goran MI, Sell SM (1998) The etiology of obesity: relative contribution of metabolic factors, diet, and physical activity. Am J Med 105(2): 145-150.

17. Bouchard CB (1994) Genetics of obesity: overview and research direction. In: Bouchard CB (Ed.), The genetics of obesity. CRC Press, USA, pp. 223-234.

18. Mathieu P, Lemieux I, Despres JP (2010) Obesity, inflammation, and cardiovascular risk. Clin Pharmacol Ther 87(4): 407-416.

19. McQuaid SE, Hodson L, Neville MJ, Dennis AL, Cheeseman J, et al (2011) Down regulation of adipose tissue fatty acid trafficking in obesity: a driver for ectopic fat deposition? Diabetes 60(1): 47-55.

20. Lee YH, Pratley RE (2005) The evolving role of inflammation in obesity and the metabolic syndrome. Curr Diab Rep 5(1): 70-75.

21. Price RA (2002) Genetics and common obesities: background, current status, strategies and future prospects. In: Wadden TA, Stunkard AJ (Eds.), Handbook of obesity treatment. New York, pp. 72-94.

22. Walfish S, Vance D, Fabricatore AN (2007) Psychological evaluation of bariatric surgery applicants: procedures and reasons for delay or denial of surgery. Obes Surg 17(12): 1578-1583.

23. Kalarchian MA, Marcus MD, Levine MD, Courcoulas AP, Pilkonis PA, Ringham RM, et al. (2007) Psychiatric disorders among bariatric surgery candidates: relationship to obesity and functional health status. Am J Psychiatry 164(2): 328-334. 


\section{Current Research in Diabetes \& Obesity Journal}

24.Zimmerman M, Francione Witt C, Chelminski I, Young D, Boerescu D, et al. (2007) Presurgical psychiatric evaluations of candidates for bariatric surgery, part 1: reliability and reasons for and frequency of exclusion. J Clin Psychiatry 68(10): 1557-1562.

25. Greene RL (2000) The MMPI-2: an interpretive manual. Needham Heights: Allyn \& Bacon 2000: 1-696.

26. Haggard RA, Stowell AW, Bernstein D, Robert J Gatchel (2008) Relationship between the MMPI-2 and psychosocial measures in a heterogeneous pain population. Rehab Psychol 53(4): 471-478.

27. Maddi SR, Khoshaba DM, Persico M, Bleecker F, VanArsdall G (1997) Psychosocial correlates of psychopathology in a national sample of the morbidly obese. Obes Surg 7(5): 397-404.
28. Stunkard AJ, Wadden TA (1992) Psychological aspects of severe obesity. Am J Clin Nutr 55: 524S-532S.

29. Charles SC (1983) The psychological status of morbidly obese patients Integr Psychiatry 1: 122-125.

30. Powers PS, Perez A, Boyd F, Rosemurgy A (1999) Eating pathology before and after bariatric surgery: a prospective study. Int J Eat Disord 25(3): 293-300.

31. Niego SH, Kofman MD, Weiss JJ, Geliebter A (2007) Binge eating in the bariatric surgery population: a review of the literature. Int J Eat Disord 40(4): 349-359.

Your next submission with Juniper Publishers will reach you the below assets

- Quality Editorial service

- Swift Peer Review

- Reprints availability

- E-prints Service

- Manuscript Podcast for convenient understanding

- Global attainment for your research

- Manuscript accessibility in different formats

( Pdf, E-pub, Full Text, Audio)

- Unceasing customer service

Track the below URL for one-step submission https://juniperpublishers.com/online-submission.php 